\title{
Research on the Development and Energy-saving of Assembling Box Buildings
}

\author{
Li Yang ${ }^{1}$, Kuan Zhou ${ }^{1 *}$, Sarah Salah ${ }^{1}$, and Shuai Zhang ${ }^{1}$ \\ ${ }^{1}$ College of Architecture \& Urban Planning, Tongji University, Key Laboratory of Ecology and Energy Saving Study of Dense Habitat, \\ Ministry of Education, Shanghai, China
}

\begin{abstract}
Since the new era, the advancement of construction industrialization has been the focus of national attention. As an important part of the assembling building system, the box structure building has a high degree of industrialization, and has considerable development potential and industrial market. This paper first illustrates the development of box-structured buildings, and sorts out the background of box-structured buildings from foreign related theories and specific projects. Subsequently, the performance characteristics and deficiencies of box buildings in the specific construction under the current technical means are described. The paper also explores the energy efficiency of box buildings. Finally, the paper concludes with an outlook on the future development of box buildings.
\end{abstract}

\section{Introduction}

Box buildings are prefabricated buildings with a high degree of industrialization. The buildings are assembled from factory-made, box-shaped building components. At present, under the background of building energy consumption accounting for $50 \%$ of the natural raw materials we have obtained [1], the emergence and development of box buildings undoubtedly provides a new direction for research on building energy efficiency. Different from the narrow concept of building energy consumption, which is limited to the energy required in the use of buildings, building energy consumption in a broad sense covers various aspects of energy loss such as building materials, building construction, and even the urban environment ${ }^{[2]}$. Assembling Box Buildings have unique advantages in these aspects, thus becoming the focus of China's construction industry in the new era.

\section{Proposal and development of the concept of assembling box buildings}

The prototype of assembling box buildings can date back to 1901, when Russia was the first to try to build boxshaped houses by wood ${ }^{[3]}$. Along with the great breakthrough of architectural theory and industrial technology in the last century, the materials, structures and building types of box buildings have developed to a certain extent. After World War II, due to the destruction of the war, many cities needed to urgently rebuild a large number of houses, which greatly promoted the industrialization of buildings and the development of assembling box buildings. In 1952, Le Corbusier's Marseille Apartment was completed. The building is also a representative piece of his architectural industrialization.
As shown in Figure 1, in his "functional insertion" sketch, the concept of Marseille Apartment is very close to the connotation of box buildings. In 1959, the first four-story box building was built in the Nakhodka region of the USSR. Subsequently, this new type of multi-layer box structure construction technology was widely used in various regions of the Soviet Union. Sochi, Moscow, Rostov and other places have successively built many multi-layer box apartments and other civil buildings ${ }^{[4]}$. But on the whole, box buildings had not yet attracted enough attention of architectural theory in the world.

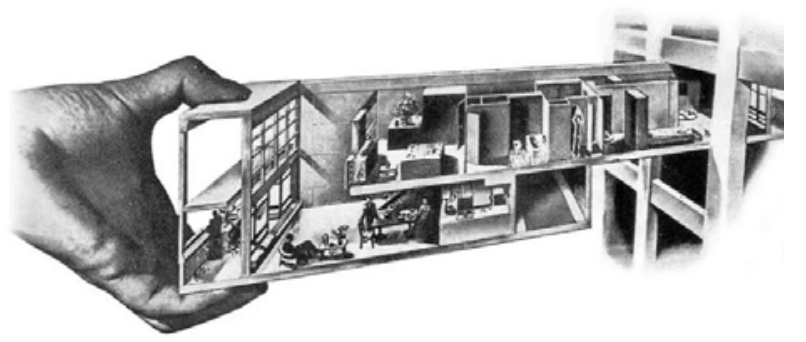

Fig. 1. Conceptual sketch of Marseille Apartment

https://www.sohu.com/a/291319353_823383 
The change occurred in 1967, in the World Expo in Montreal, architect Moshe Safdie 's work "Habitat 67" caused a sensation with its peculiar appearance. As shown in Figure 2, in this architectural work, all the residential units are set by the architect as a unified box module, prefabricated in advance, and then stacked staggered to form such a unique shape. The building showed some possible structural forms and functions of the box unit. Since then, especially in the subsequent 1970s, boxstructured buildings had developed more rapidly. Except for Europe, which has a long history of contacting with box buildings, relevant practices also appeared in the United States and Japan. Generally speaking, at the time, the United States, the Soviet Union, and Germany produced most of the box building components, and their output accounted for about $90 \%$ of the world's total output.

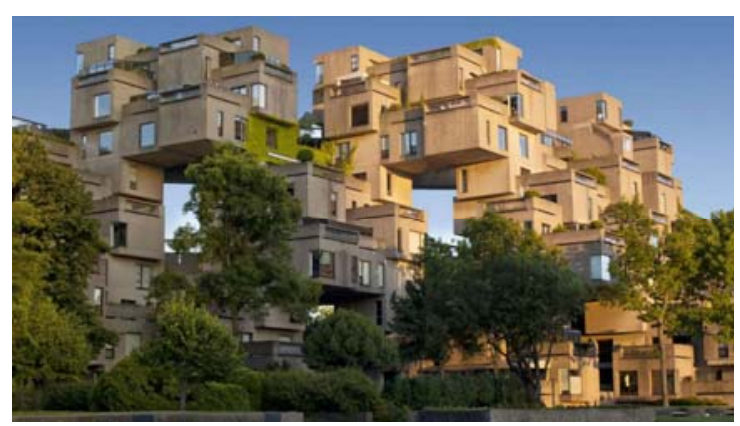

Fig. 2. Moshe Safdie 's Habitat 67

https://www.sohu.com/a/151130299_275005

The Soviet Union, where box buildings first appeared, focused on giving play to its industrial advantages and developing high-rise box building systems. In 1969, a nine-story box building was first built in Krasnodar. At the same time, the box buildings have made breakthroughs in building functions. Public buildings such as nursing homes, shops, office buildings, etc. had gradually appeared, adopting this technology. In the National Economic Development Plan from 1981 to 1990, the Soviet Union even regarded the development of box buildings as a key point.

However, related architectural theories about box buildings mainly appear in capitalist camp countries such as France, the United States, and Japan. As early as the 1950s, French pioneer architect Yona Friedman put forward a series of theories such as "mobile architecture" and "air city". As shown in Figure 3, in his theory, the user's participation and variability of the building are highly emphasized. He believes that the residents should be the designer of the building, and the building should change with the change of society. In many of his sketches, the image of the box building has appeared many times, indicating the plasticity of this structural form. Subsequently, ideas on building development were also presented by the British Archigram team. Among them, the unitization and mobility of buildings are the essence of their theory. In their famous "plug-in city" concept, each house has become a living box unit, which can be freely inserted into the building structure. At the same time, the box itself can be transported freely, and the installation process is integral.

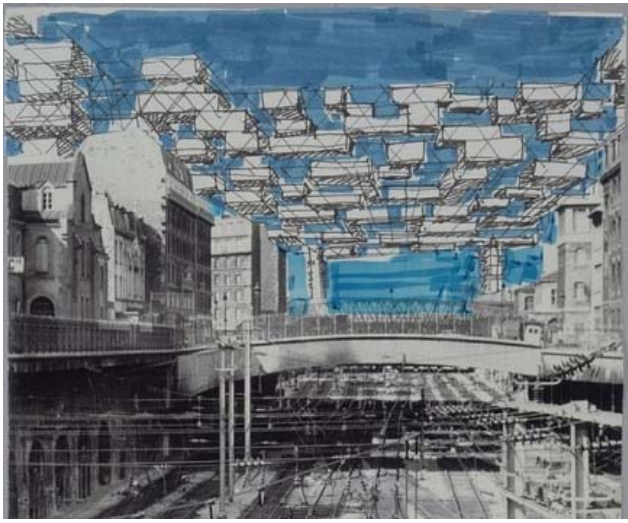

Fig. 3. Yona Friedman 's conception of Air City

http://huaban.com/pins/1396691635/

In 1970, at the Osaka International Expo, Japanese architect Kisho Kurokawa created the box-shaped TB Experimental House, which is a theoretical version of his "metabolism". The core idea is that the building should not be static and immutable, but should have a certain vitality. Like the living thing, it is always in the dynamic process of metabolism. The box building can fully represent the development possibilities that the building should have. Because of the form of its prefabricated standardized module, the original structural support is not to be changed when you want to change the building. And only the appropriate replacement of some components as well as the changes of the number or positions of the boxes are needed to achieve the growth and metabolism of the building. In 1972, as shown in Figure 4, in the design of his famous Nakagin Capsule Tower, the architectural form of a box structure is also used. 140 regular rectangular cabins were inserted as living units in the two cylinders in the center. These cabins can be replaced, increased or decreased at any time. By taking advantages of the flexibility and modular structure of box buildings, it achieved the original intention of "metabolism" [5].

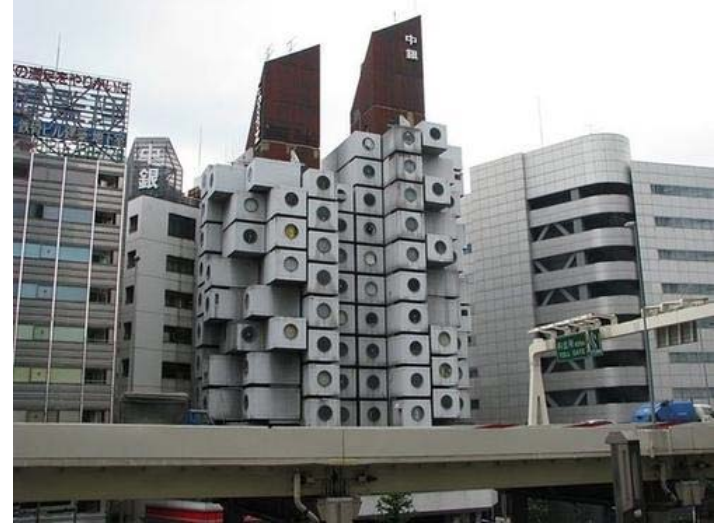

Fig. 4. Nakagin Capsule Tower

https://pcedu.pconline.com.cn/sj/design_area/excellent/0903/16 03263_2.html

By 1983, the modularized container construction theory system was first proposed by John M. Di. Martino in the United States. This system skillfully combined the 
reuse of containers with the architectural design concept. It is still a commonly used method of lots of constructions. During the 1991 Gulf War, the US military invested a large number of container-type modular buildings in order to solve the problem of prisoners of war and temporary accommodation and office work of the army. This was the first large-scale practical application of container buildings ${ }^{[6]}$.

Since then, the research on box buildings had gradually deepened in various countries, and the related technical methods had gradually been more advanced, and the market had also expanded year by year. In terms of the building types of applications, it is no longer limited in residence but also has cultural, tourist, commercial, office and hotel functions.

\section{Performance characteristics of assembling box buildings}

Box structure building is an advanced form of building industrialization, and its core lies in standardized, modular prefabricated assembly.

Firstly, it needs shorter construction time. Since most of the construction work of the box buildings has been completed in the factory, it is only necessary to be responsible for the box insertion and connection work at the construction site, which is basically a dry operation, thus greatly reducing the on-site workload and the construction time. The related components can also be adapted to the rapid modern transportations such as highway, railway, and waterway. However, due to the large component size, the assistance of related equipment is required.

Secondly, for the sake of industrialized production, the components of the box structure buildings are relatively standardized, and the large machine production process in the factory reduces the omissions and errors that are prone to occur during manual construction, thereby ensuring the overall quality.

Thirdly, from the aspect of structure, box buildings have the characteristics of strong integrity and high safety performance. Since each box is an independent support, its mechanical properties are high. And the uniform concrete pouring and assembling of the box also guarantee the integrity of each box. Even if the box is inserted as a filler, it will have the dual structure guarantee of the box itself and the frame, ensuring the overall stability and strong earthquake or wind resistance.

The flexibility of the box building is particularly commendable, which is why it has become the protagonist of many architectural ideas mentioned above. Regardless of whether the building with a box structure is temporary or permanent, as long as adjustment or reconstruction is needed, the corresponding prefabricated components can be easily replaced and the overall spliced form of the building can be changed. Even if it is required to be relocated as a whole in accordance with the requirements of urban planning, it can be quickly decomposed and then rebuilt, instead of being irreversibly demolished, thereby enhancing its sustainability and economy.
Box buildings have the characteristics of standardization and modularity, which also leads to greater repetitiveness of the space. Therefore, in terms of functions, it is more adaptable to uniform building types such as residences, dormitories, hotels, schools, and office buildings. However, it is difficult to adapt to large-span spaces, or to the types of buildings that have more complex functional requirements and more spatial changes.

From the perspective of economy, the common construction cost which includes factors such as labor and material consumption is only about 1569.77 yuan $/ \mathrm{m}^{2}$ for small high-rise buildings. And it is 2179.21 yuan $/ \mathrm{m}^{2}$ when using the box structure. And the construction cost difference between the two is 609.44 yuan $/ \mathrm{m}^{2}$. Therefore, if the subsequent maintenance costs are ignored, the construction cost of buildings with common structure is lower. However, if the maintenance costs are considered together, buildings with common structure require various component installation and wall pouring costs while box buildings only need to bear the connection costs between the box and the whole. As a whole, the construction cost of box buildings is relatively lower ${ }^{[7]}$.

In addition, box structure buildings have also encountered some resistance in practical applications. First of all, the manufacturing of box structure components is expensive compared to other types of buildings. Factories require large capital investment, but there are not many projects that actually use this structure, which easily exposes the factory to greater economic risks and many companies are discouraged. The transportation and installation of related components and materials require specific large-scale equipment, which also leads to an increase in the overall price burden. In terms of architectural space, as the related research and design work in China is still in the experimental stage, it is not good enough as a whole. Considering the limitations of the building itself, the current living experience needs to be improved. Coupled with the lack of public understanding of box buildings and low social recognition, they generally hold a conservative wait-and-see attitude.

\section{Energy efficiency of box buildings}

As for the energy efficiency of box buildings, it is a complex topic. In China, due to the lack of awareness of building energy saving in the past, a large number of houses still use brick-concrete structure. At the time, the outer walls of box-structured buildings mostly had polystyrene foam inside with very low thermal conductivity. And the thermal resistance value is about $1.2 \mathrm{~m}^{2} \mathrm{~K} / \mathrm{W}$ in actual laboratory and engineering tests. While the resistance of $49 \mathrm{~mm}$ brick walls in brickconcrete structure houses is only $0.79 \mathrm{~m}^{2} \mathrm{~K} / \mathrm{W}$. According to the calculation at that time, if 100,000 square meters of brick-concrete buildings was replaced with box structures, a land of $125 \mathrm{mu}$ and 43,752 tons of standard coal could be saved ${ }^{[8]}$. It can be seen that the energy efficiency of the box building was more prominent at the time and can save energy and land, reduce environmental and air pollution. 
However, with the progress of the domestic construction system, brick-concrete houses have gradually been replaced by new structures and materials, and the country has also paid more and more attention to building energy efficiency and the advantages of box buildings are not outstanding enough ${ }^{[9-10]}$. From the perspective of construction energy consumption, due to various influences such as shape, materials, and connection methods, the building of box structure may generate more energy consumption than a building of common structure with specific design if they were on the same site. But from a broader perspective, the large-scale production mode can also reduce material waste, labor resources and costs, and at the same time promote the recycling of building materials, so it is relatively more energy efficient.

In Japan, related energy-saving technologies such as rainwater collecting, solar power generation, and winddriven fresh air systems have been gradually incorporated into box buildings. But in China, because the construction of these assembling box buildings is often with the purpose of increasing construction and design speed, the internal design is not sufficiently detailed and lacks considerations, there is still a large gap in energy saving in building operation and maintenance. The research of building energy efficiency is a category closely connected with the times ${ }^{[11]}$. How to find out the suitable energysaving technologies and methods when box structure buildings are gradually popular is a problem that needs further research ${ }^{[12]}$.

In addition, the selection of materials of box structure buildings are also being explored and innovated in. Except for common concrete, steel and wood, there is the practice of using SIP structural insulation boards. And its structure is shown in Figure 5. It can not only support the heat insulation but also bear the load, which greatly helps the energy saving of the building. Also, adopting reasonable environmental response strategies can promote building energy efficiency. By reasonably taking advantages of local wind and water conditions, building equipment energy consumption can be reduced ${ }^{[13-15]}$.

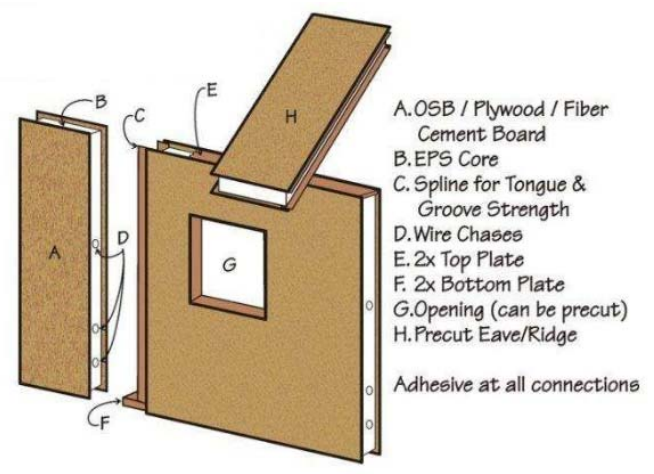

Fig. 5. SIP structure insulation board

https://m.sohu.com/a/55130624_130123

\section{Summary and outlook}

As a representative of building industrialization, box structure buildings have been gradually accepted and promoted by the world since its emergence in the last century with its unique industrial characteristics and construction advantages. As of the 1960s, box-structured buildings had been extensively tried and applied to residential buildings in the Soviet Union, the United States, and other countries. Subsequently, box buildings were valued by many architects and architectural theorists for its flexible, variable, and modular characteristics. Yona Friedman's "mobile building" and "air city" ideas, the British Archigram architects' concept of "plug-in city and Japanese architects' "metabolism" are all the good examples. With the improvement of industrialization and the advancement of technology, the forms of box buildings are also gradually developing, and the container building that is popular in recent years is one of them.

From the perspective of technological development, box buildings still mainly emphasize its assembly characteristics and industrial construction advantages. But how to strengthen the its comfort, and how to go further and realize its potential of energy saving technology under the premise of ensuring its comfort ${ }^{[16]}$, how to reduce the energy consumption during building operation by combining with its structural characteristics have become needed researching contents.

In China, the period of extensive development of the construction industry has just passed, and the country vigorously promotes the development of construction industrialization. But in general, the research and practical application of assembling buildings is still in its infancy. With the increasing tension of urban space and land resources, high efficiency and high industry have become the goals pursued. Therefore, the construction industry has higher and higher requirements for intensification, scale, and modularity. As a typical representative of assembling buildings, box buildings will have a broader prospect.

\section{References}

1. Yang L, Liu X.D, Qian F. J. Cleaner Prod, 209, 886902(2019)

2. Yang L. Housing Sci. 5, 32-37(2017)

3. Tang Q.M, Chen S. Build. Construct. 04, 58-68(1984)

4. Gu J.H. Archit. Technol, 12, 42-45(1984)

5. Liu Y.J, Gao L. Sichuan Archit. 05, 136-138(2008)

6. Gao Z.J. City \& House, 26, 12-16(2019)

7. Yang X.Z, Li X.W. Low Temp. Archit. Technol. 39, 128-131(2017)

8. Zhao G.H. Housing Sci. 1, 37-39(1997)

9. Qian F, Yang L. Build Sci, 33, 202-207(2017)

10. Qian F, Shi Z.D, Yang L. Build Sci, 35, 164-169(2019)

11. Yang L. Green Building Design: Building Energy Efficiency (Tongji University Press, Shanghai, 2016)

12. Yang L, Liu X.D, Qian F. J. Energy \& Build, 207, 109613(2020)

13. Qian F, Yang L. Archit. J, 2, 114-118(2017)

14. Yang L, Liu X.D, Qian F, Sustain. Cities. Soc, 55, 102019(2020) 
15. Yang L, Liu X.D, Qian F, Indoor. Built. Environ, 28, 1104-1125(2019)

16. Qian F, Tang S.N. Build Sci, 34, 106-111(2018) 